\title{
LOGIC-BASED APPROACH FOR EVALUATING CHANGE IMPACTS
}

\author{
Wei-Chih Wang and Ya-Ling Chiu ${ }^{2}$ \\ ${ }^{1}$ Assistant Professor, ${ }^{2}$ Graduate Student, Department of Civil Engineering, \\ National Chiao-Tung University, Hsin-Chu, Taiwan
}

\begin{abstract}
As the complexity of a construction project increases, the occurrence of changes becomes unavoidable. In addition to the direct impact, a change may also have consequential impact (ripple effect) on the performance of project duration and cost. Built on a schedule network, this paper proposes a model, called LOGIC that uses a logic-based (including hard logic, soft logic, and causal logic) approach to quantitatively capture the consequential impact. In the paper, an example is used to demonstrate the strengths of the model. Strategies of computer implementation and recommendation for future work are also provided.
\end{abstract}

Keywords: changes, hard logic, soft logic, causal logic, consequential impact.

\section{INTRODUCTION}

A change or change order represents a modification to the original contract scope. As the complexity of a construction project increases, the occurrence of changes becomes unavoidable. The changes often have adverse impacts on the duration and cost of a project. Such impacts may include direct impact and consequential impact (ripple effect). As also defined in the Construction Industry Institute (CII) in 1993 [2], this paper considers the direct impacts of changes are results experienced within the scope of the changed activity; and consequential impacts of changes are results of such changes that are experienced elsewhere on the project.

In practice, the direct impacts on duration may be easily computed by comparing the as-planned and asbuilt schedules, and the direct impacts on cost can be obtained according to the changed quantity of work (e.g., addition or deletion of work, or revision and substitution of work). What is normally arguable is the quantitative evaluation of consequential impacts.

The existence of consequential impact can be proven in a way that change impacts may progpogate a series of a productivity loss caused by resource idling, overmanning, congestion, and overtime, etc. The cause and effect of consequential impacts is complicate especially for some concurrent and successive activities which may or may not located at the same network paths as the changed activities. This complexity of evaluation explains the reason why the disputes, claims, and legal litigations between construction parties frequently occur.
Focusing on the owner-directed changes, this paper proposes a logic-based approach for quantitatively evaluating the impact of changes. The approach integrates several types of logical relatiohsips to capture the key concerns viewed by different parties on assessing the change impacts.

\section{THE PROBLEM}

If an owner-directed change can be shown to delay the completion date of a project, a time extension is normally granted for the contractor. The costs of extra or less amount of work can also be easily obtained by computing the contractual unit price multiplying by the change quantity. And if the cost data are well documented, some overhead burdens, extra supervisory and staff expenses may be treated as direct costs and are likely to be compensated.

However, as long as the activity durations are delayed, the contractor believes that a consequential cost of change be compensated for accelerating the work (by shifting work, working overtime, increasing crew sizes, etc), overcoming the loss of productivity (due to bad job rhythm, morale, and learning curve), and recovering the loss of float flexibility. Sometimes a time extension may even be proposed because some other successive non-critical activities become critical due to the loss of productivity.

On the owner's side, it is argued that many of the successive activities of changed activities can still be started (even there are precedence relationships between them), which means it is the contractor's own management problems for delaying those 
successive activities. And since those so-called consequentially affected activities have no change in their scope of work, no costs should be compensated.

The above two-side stories reveal two key concerns for resolving their differences: (1) the contractual logical relationships between network activities are traditionally assumed to be hard or fixed; and (2) it is difficult to provide evidence to prove a quantitative value of losing productivity (even under a well-defined project documentation process). Therefore, a practical model for evaluating the impacts of change should be capable of taking the two key concerns into consideration.

\section{PAST RESEARCH}

This paper focuses on the compensable impacts of changes, such as additions, late delivery of owner materials, drawings, and permits. The excusable-andnoncompensable impacts (such as strikes and force majeure) and noncompensable impacts (such as late mobilization and lack of equipment by the contractor) are out of the scope of this paper.

Currently, the most widely used method in evaluating the change impact is the CPM (Critical Path Method) schedule analysis method [1]. This method is applied based on three kinds of schedules: as-planned, as-built and as-impacted schedules. The as-impacted schedule is the schedule that adds delays to the as-planned schedule. By comparing the asplanned and as-impacted schedules, a compensable delay can be calculated. And by comparing the asbuilt and as-impact schedules, a cost compensation of acceleration improvement can be obtained. Obviously, since the contractor dominates the work, the amount of extra cost to improve the performance of the as-built schedule is debatable. And this method still cannot explicitly illustrate the impact of consequential impact because no time extension and cost compensation will be granted for the situation that the project duration is not delayed.

In 1988, John Kuprenas proposed a Change Order Management Procedure (COMP) model to assess the cost and schedule impact of construction changes [4]. The COMP model demonstrates the feasibility of using influence diagrams to quantify the consequential impacts of changes. As the author noted, nevertheless, the COMP model is deficient in that it requires a great number of conditional probability assessments of influence diagram nodes for assessing a particular consequential impact.

In 1993, Sonthya Vanichvatana developed a Change-Effect Prediction (CEP) model for predicting the consequential impacts that occur during construction [5]. The CEP model is built on network precedence scheduling by attaching a Standard Template Diagram (STD) to each schedule activity. In addition, profound change cause-effect pairwise relationships and a knowledge-based system are required to execute the CEP model. The CEP model has contributed to a great in-depth understanding of consequential impacts, especially in the propagation concept of change prediction. However, applying the CEP model to the industry is not a easy job because intensive site-level data for each schedule activity and complicated data of rule-like pairwise relationships are required.

In conclusion, the existing methods still can not meet the two keys to solve the problem formalized in the previous section. A new model is thus needed.

\section{THE LOGIC MODEL}

Built on the CPM schedule analysis method for evaluating direct impacts, the propsoed model called LOGIC has two additional features. First, the model recognizes the fact that the network logical relationships are not alawys fixed. The sequential relationships between some activities may be reversable (i.e., switching activities' sequences), or even can be ignored (i.e., executing activities simultaneously). In other words, the precedence relationships could be soft. And the decision to select one sequence over the others is sometimes based on management criteria, rather than physical constraints. Second, the model proposes the use of causal links between activities to trace consequential impact of losing productivity. The LOGIC model can be graphically overviewed in Figure 1.

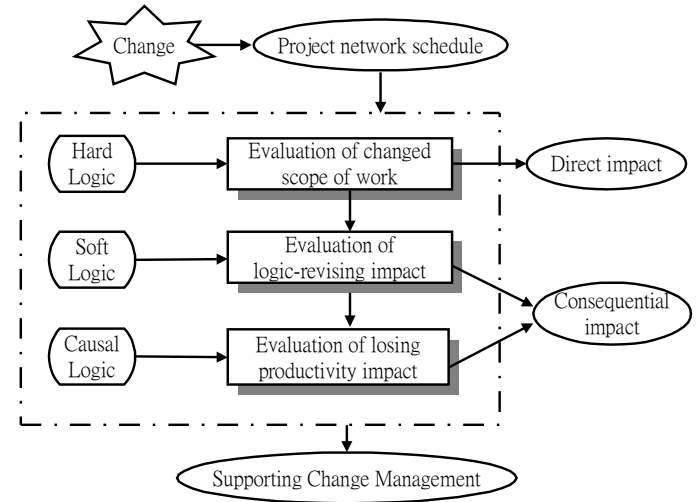

Figure 1. The LOGIC Model

\subsection{Evaluation of Direct Impacts}

Figure 2 shows the process of evaluating direct impacts of change. The first step is to determine the amount of changed quantity of work. The impact cost for each changed activity is the amount of changed quantity multiplying by the unit price per quantity. And the total direct impact of cost of change $\left(C_{1}\right)$ is the summation of the impact costs of all changed activities. Regarding of the duration aspect, since the affected activity durations are changed, the project duration will also vary. The impact on duration is thus the difference between the 
new project duration $\left(\mathrm{D}_{1}\right)$ considering the impact of direct change and the original project duration $\left(\mathrm{D}_{0}\right)$.

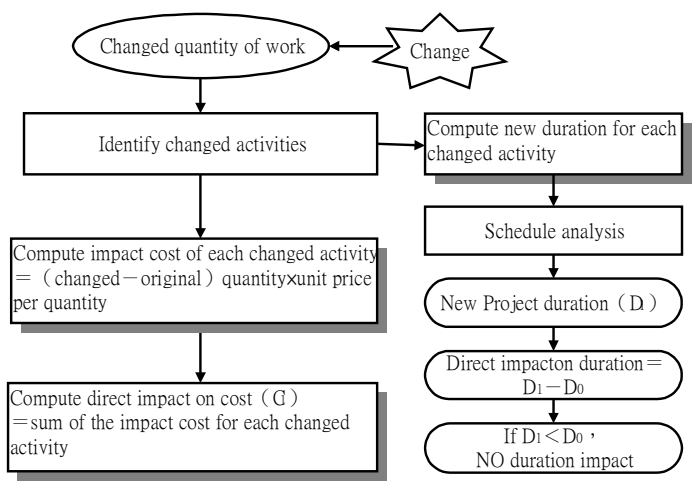

Figure 2. Evaluation of Direct Impacts

\subsection{Types of Logical Relationships}

The LOGIC model classifies the schedule network logical relationships or links into three types: hard logic, soft logic, and causal logic. Hard or fixed logic is the network logic that has a single precedence relationship between activities because of some physical constraints. Soft logic is the logical relationship that has several possible alternatives for completing the job. The LOGIC model adopts the three types of soft links, as defined in Amr El-sersy in 1991 [3]: SOFT, OR, and EXCLUSIVE-OR links. Causal logic is the logical link that indicates the influential relationship between activities. Causal logic is similar to the ARC used in the influence diagrams and causal models $[4,5]$. The characteristics and examples of different types of links are shown in Figure 3.

\section{(1) FIXED Link}

- A must precede B

- Example : Excavate footings $\rightarrow$ Set footing forms

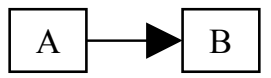

(2) SOFT Link (reversable and ignorable)

- A can precede B

- B can precede A

- A B can be scheduled simultaneously

- Example: Excavate area $\rightarrow$ Excavate area2

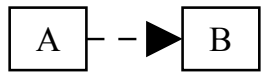

(3) OR Link (ignorable)

- A can precede B

- A V B can be scheduled simultaneously

- Example : Drive piles area $1 \rightarrow$ Drive piles area2
(4) EXCLUSIVE-OR Link (reversable)
A can precede B
- B can precede A
- Example : Excavate area $\rightarrow$ Install piles

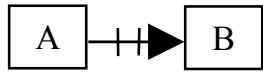

(5) CAUSAL Link

- The delay of A results in a productivity loss for B

- Example : Wooden

Windows $\rightarrow \rightarrow$ Wooden Doors

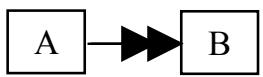

Figure 3. Types of Logicl Relationships

\subsection{Impacts of Revising Soft Links}

The main objective of providing logic alternatives is to reduce project completion time. Figure 4 presents the process of evaluating the impacts of revising soft links. If the new project duration $\left(D_{1}\right)$ considering the direct impact of change is shorter than the original project duration $\left(\mathrm{D}_{0}\right)$, no links should be revised to further shorten the contractual project duration. This is because there will be no impact on duration, and thus no need to revise soft links. However, the cost of direct impact $\left(\mathrm{C}_{1}\right)$ still exists and the consequential impact cost of losing productivity $\left(\mathrm{C}_{3}\right)$ may exist, as the cost of revising links $\left(\mathrm{C}_{2}\right)$ is zero.

On the other hand, if $\mathrm{D}_{1}>\mathrm{D}_{0}$, the LOGIC model looks for a $\mathrm{D}_{2}$ that has a $\mathrm{D}_{2}<\mathrm{D}_{1}$ condition. If such a $D_{2}$ exists, the duration impact is then equal to $D_{2}-D_{0}$ with an additional $\mathrm{C}_{2}$. And if no $\mathrm{D}_{2}<\mathrm{D}_{1}$ exists, the duration impact is $\mathrm{D}_{1}-\mathrm{D}_{0}$ and $\mathrm{C}_{2}$ is 0 , as $\mathrm{C}_{3}$ may exist.

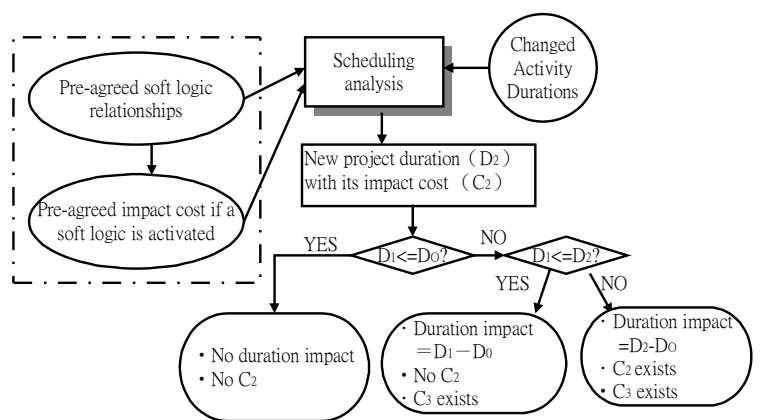

Figure 4. Evaluation of Revising Links 
Table 1. Example of Pre-agreed Consequential Impact Costs Caused by Revising Links

\begin{tabular}{|c|c|c|c|c|}
\hline $\begin{array}{l}\text { Planned } \\
\text { Logic }\end{array}$ & Management Concerns & $\begin{array}{l}\text { Revised } \\
\text { Logic }\end{array}$ & Management Decisions & Agreed Impact Cost \\
\hline \multirow[t]{4}{*}{$\mathrm{A} \rightarrow \mathrm{B}$} & Limited equipment, labor, space & $\mathrm{B} \rightarrow \mathrm{A}$ & Only switching activities & 0 \\
\hline & Limited budget & $\mathrm{B} \rightarrow \mathrm{A}$ & Obtain $\Delta$ cash $(=\$ B-\$ A>0)$ & $\begin{array}{l}\text { Interest rate } \times \Delta \text { cash (if } \\
\Delta \text { cash }>0 \text { ); otherwise } 0\end{array}$ \\
\hline & $\begin{array}{l}\text { Bad weather condition is expected } \\
\text { for activity B }\end{array}$ & $\mathrm{B} \rightarrow \mathrm{A}$ & $\begin{array}{l}b=\text { Productivity loss rate } \\
\text { for B per unit }\end{array}$ & $\mathrm{b} \times$ quantity $\times$ unit price \\
\hline & Alternative work location & $\mathrm{B} \rightarrow \mathrm{A}$ & Only switching & 0 \\
\hline \multirow[t]{5}{*}{$\mathrm{A} \rightarrow \mathrm{B}$} & Limited equipment, labor & $\begin{array}{l}\mathrm{A} \\
\mathrm{B}\end{array}$ & $\begin{array}{l}\text { Add required resources to } \\
\text { B }\end{array}$ & $\begin{array}{l}\text { Cost of renting, buying, or } \\
\text { hiring more resources }\end{array}$ \\
\hline & Limited space & $\begin{array}{l}\mathrm{A} \\
\mathrm{B}\end{array}$ & $\begin{array}{l}b=\text { Productivity loss rate } \\
\text { for B per unit }\end{array}$ & $\mathrm{b} \times$ quantity $\times$ unit price \\
\hline & Limited budget & $\begin{array}{l}\mathrm{A} \\
\mathrm{B}\end{array}$ & Obtain more cash $=\$ B$ & Interest rate $\times \$ B$ \\
\hline & $\begin{array}{l}\text { Bad weather is expected condition } \\
\text { for activity B }\end{array}$ & $\begin{array}{l}\mathrm{B} \\
\mathrm{A}\end{array}$ & $\begin{array}{l}b=\text { Productivity loss rate } \\
\text { for B per unit }\end{array}$ & $\mathrm{b} \times$ quantity $\times$ unit price \\
\hline & Alternative work location & $\begin{array}{l}\mathrm{A} \\
\mathrm{B}\end{array}$ & Add required access B & Cost of adding the access \\
\hline
\end{tabular}

From the viewpoint of risk sharing, it is appropriate to assume that the contractor has the right to execute the project by revising network logic (although the contractual project network remains the same). Therefore, a logic-revising decision called by the owner (for issuing the change) has to pay the cost for taking the flexibility out of the contractor. Due to the complexity of evaluating the cost of revising the soft links [3], the LOGIC model suggests that both parties determine the costs in advance. The costs should be determined considering the characteristics of activities and types of resources involved. For example, the considerations may include the amounts of resources at some point in time exceeding their maximum available quantities and undesirable variability in the patterns for some resource profiles [3]. Table 1 shows an example of possible criteria in deciding the costs.

\subsection{Consequential Impacts of Losing Productivity}

Computing an accurate cost value of losing productiviy is even more difficult and complex [5]. Unlike the CEP model focusing on the site-level data [5], the LOGIC model stays with the level of contractual project network for believing that relying on a time-consuming effort of collecting interrelated site-level data (such as concrete haul distance, placing location, and so on for only a concreting activity) is not practical.

The LOGIC model uses the concept of causal logic to trace the consequential impacts of losing productivity occurring in the activities that have no physically interconnected relationships with the affected activities due to the change. As shown in Figure 5, the causal links and their associated impact costs are also suggested to be pre-determined by both the owner and contractor. Table 2 presents an example of how the impact cost may be computed.
Figure 5. Evaluation of Losing Productivity Impacts

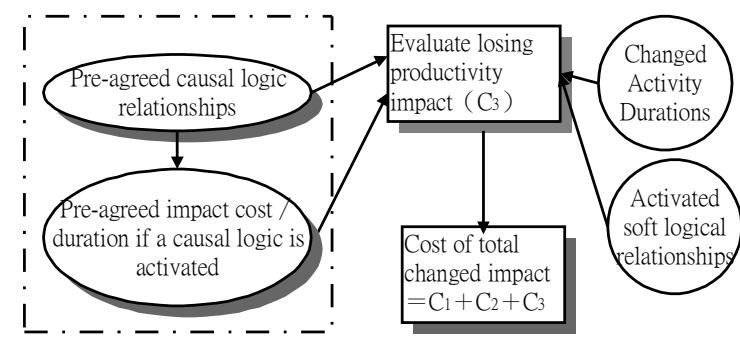

Table 2. Example of Consequential Impact Costs Caused by Losing Productivity

\begin{tabular}{|c|l|l|l|}
\hline $\begin{array}{c}\text { Causal } \\
\text { Logic }\end{array}$ & \multicolumn{1}{|c|}{ Cause } & $\begin{array}{c}\text { Effect } \\
\text { (productivity loss) }\end{array}$ & \multicolumn{1}{|c|}{$\begin{array}{c}\text { Impact } \\
\text { Cost }\end{array}$} \\
\hline $\begin{array}{c}\text { A } \rightarrow \rightarrow \text { B B } \\
(\#)\end{array}$ & $\begin{array}{l}\text { If A's start } \\
\text { time is revised } \\
\text { by one day }\end{array}$ & $\begin{array}{l}\mathrm{b}=\text { extra labor- } \\
\text { hour cost per day } \\
\text { for B }\end{array}$ & $\begin{array}{l}\mathrm{b} \times \\
\text { laberers }\end{array}$ \\
\hline
\end{tabular}

\#: An example of cause-effect path [5]: crowding interference $\rightarrow$ site access problem $\rightarrow$ poor site condition $\rightarrow$ poor worker mental $\rightarrow$ productivity loss

\section{A DEMONSTRATION EXAMPLE}

\subsection{Description of the Example}

As shown in Figure 6, assume that there is an 11activity example project network associated with three kinds of soft link and one causal link. (An OR link for activities $\mathrm{C}$ and D; a SOFT link for E and F; an EXCLUSIVE-OR link for $\mathrm{H}$ and $\mathrm{I}$; a CAUSAL link between $\mathrm{C}$ and J.) The project has a 23-day duration. The details of network activity $\mathrm{B}$ are provided in Table 3 . 


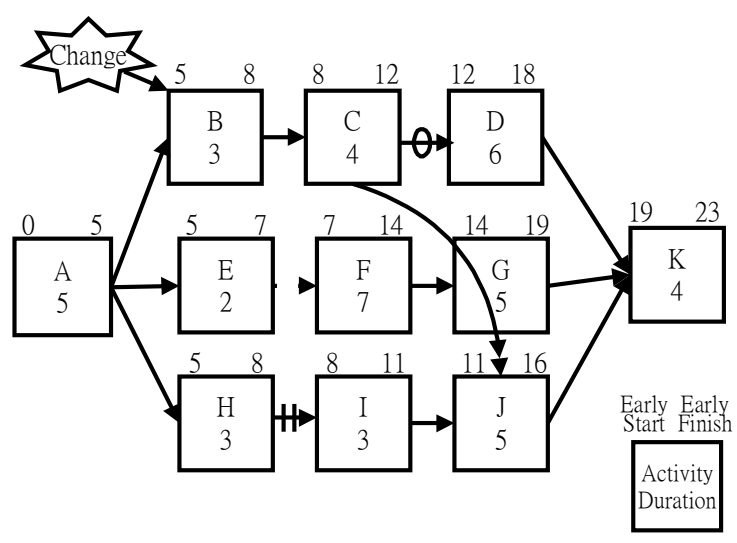

Figure 6. Network of Example Project

Table 3. Detailed Contents of Activity B

\begin{tabular}{|l|l|}
\hline Activity & \multicolumn{1}{|c|}{ Detailed Contents } \\
\hline \multirow{4}{*}{ B } & Amount of work quantity $=60$ units \\
\cline { 2 - 2 } & Unit price $=\$ 2,000$ per unit \\
\cline { 2 - 2 } & Productivity $=0.05$ days per unit \\
\cline { 2 - 2 } & Duration $=3$ days \\
\hline
\end{tabular}

Table 4 and Table 5 present the pre-agreed impact costs of revising planned logical relationships and the impact costs of losing productivity, respectively.

Table 4. Pre-agreed Impact Cost of Revising Links

\begin{tabular}{|c|c|c|}
\hline Original Link & If revised to & Impact Cost \\
\hline $\mathrm{C} \rightarrow \mathrm{D}$ & $\begin{array}{c}\mathrm{C} \\
\mathrm{D}\end{array}$ & 15,000 \\
\hline $\mathrm{E} \rightarrow \mathrm{F}$ & $\mathrm{E}$ & 10,000 \\
\hline $\mathrm{E} \rightarrow \mathrm{F}$ & $\mathrm{F} \rightarrow \mathrm{E}$ & 8,000 \\
\hline $\mathrm{H} \rightarrow \mathrm{I}$ & $\mathrm{I} \rightarrow \mathrm{H}$ & 5,000 \\
\hline
\end{tabular}

Table 5. Pre-agreed Impact Cost of Losing Productivity for Link $\mathrm{C} \rightarrow \rightarrow \mathrm{J}$

\begin{tabular}{|c|l|l|l|}
\hline $\begin{array}{c}\text { Causal } \\
\text { Logic }\end{array}$ & \multicolumn{1}{|c|}{ Cause } & \multicolumn{1}{|c|}{ Effect } & $\begin{array}{c}\text { Impact } \\
\text { Cost } / \text { day }\end{array}$ \\
\hline $\mathrm{C} \rightarrow \rightarrow$ J J & $\begin{array}{l}\text { If C's start time } \\
\text { is revised by 1 } \\
\text { day }\end{array}$ & $\begin{array}{l}\text { bextra } \$ 4,000 \\
\text { per laborer per } \\
\text { day for J }\end{array}$ & $\begin{array}{l}\$ 4,000 \times 3 \\
\text { laberers }\end{array}$ \\
\hline
\end{tabular}

As also shown in Figure 6, suppose there is a change affecting the scope of work for activity $\mathrm{B}$, and the amount of quantity of activity $B$ has increased from 60 units to 100 units (i.e., extra work of 40 units).

\subsection{Computations of the Impacts of Change}

In the LOGIC model, the direct impact of change on cost $\left(\mathrm{C}_{1}\right)=($ changed quantity $) \times$ ( unit price $)$ $=40$ units $\times \$ 2,000 \mathrm{NT}$ per unit $=\$ 80,000 \mathrm{NT}$. The extended duration of activity $\mathrm{B}$ due to the change $=$ $($ changed quantity $) \times($ productivity $)=40$ units $\times$ 0.05 days per unit $=2$ days. That is the new duration of $\mathrm{B}$ is five day, and the new project duration using the CPM calculations becomes 24 days. Thus, by comparing the original and new project durations, the direct impact of change on duration $\left(\mathrm{D}_{1}\right)$ is 1 day $(=$ $24-23)$.

Then the model proceeds to evaluate whether or not to revise soft links. It is found that eleven possible scenarios of new project networks could exist, as shown in Table 6. Each scenario is provided with a new project duration $\left(\mathrm{D}_{2}\right)$ and its corresponding impact cost of revising links $\left(\mathrm{C}_{2}\right)$. Since the shortest duration and minimum impact cost are of interests, scenario 1 with a shortest duration of 23 days and a minimum cost of $\$ 15,000$ is selected. Therefore, the impact of change on duration is then reduced to 0 day $\left(\mathrm{D}_{2}-\mathrm{D}_{0}=23-23\right)$, but an extra cost of $\$ 15,000$ should be compensated. The new schedule network, i.e., scenario 1, is presented in Figure 7.

Now, since activity $\mathrm{C}$ is delayed by two days (from day 8 to day 10) and the daily impact cost of the causal link $C \rightarrow J$ is $\$ 12,000$ (see Table 5), the impact cost of losing productivity is then equal to $\$ 24,000$. This means the total impacts of change on duration and cost are then equal to 0 day and $\$ 119,000$, respectively. The breakdowns of the impacts are summarized in Table 7.

Table 6. Scenarios of Varying Logical Relationships

\begin{tabular}{|c|c|c|c|c|}
\hline Scenario & $\begin{array}{c}\text { Original } \\
\text { Link } \\
\end{array}$ & $\begin{array}{c}\text { Revised } \\
\text { Link } \\
\end{array}$ & $\begin{array}{c}\text { Project } \\
\text { Duration }\left(\mathrm{D}_{2}\right)\end{array}$ & $\begin{array}{c}\text { Impact } \\
\text { Cost }\left(\mathrm{C}_{2}\right) \\
\end{array}$ \\
\hline 1 & $C \rightarrow D$ & $\begin{array}{l}C \\
D\end{array}$ & 23 & 15,000 \\
\hline 2 & $\mathrm{E} \rightarrow \mathrm{F}$ & $\begin{array}{l}\mathrm{E} \\
F\end{array}$ & 24 & 10,000 \\
\hline 3 & $\mathrm{E} \rightarrow \mathrm{F}$ & $\mathrm{F} \rightarrow \mathrm{E}$ & 24 & 8,000 \\
\hline 4 & $\mathrm{H} \rightarrow \mathrm{I}$ & $\mathrm{I} \rightarrow \mathrm{H}$ & 24 & 5,000 \\
\hline \multirow{2}{*}{5} & $C \rightarrow D$ & $\begin{array}{l}\text { C } \\
\text { D }\end{array}$ & \multirow{2}{*}{23} & \multirow{2}{*}{25,000} \\
\hline & $\mathrm{E} \rightarrow \mathrm{F}$ & $\begin{array}{l}E \\
F\end{array}$ & & \\
\hline \multirow{2}{*}{6} & $C \rightarrow D$ & $\begin{array}{l}\text { C } \\
\text { D }\end{array}$ & \multirow{2}{*}{23} & \multirow{2}{*}{23,000} \\
\hline & $\mathrm{E} \rightarrow \mathrm{F}$ & $\mathrm{F} \rightarrow \mathrm{E}$ & & \\
\hline \multirow{2}{*}{7} & $C \rightarrow D$ & $\begin{array}{l}\text { C } \\
\text { D }\end{array}$ & \multirow{2}{*}{23} & \multirow{2}{*}{20,000} \\
\hline & $\mathrm{H} \rightarrow \mathrm{I}$ & $\mathrm{I} \rightarrow \mathrm{H}$ & & \\
\hline \multirow{2}{*}{8} & $\mathrm{E} \rightarrow \mathrm{F}$ & $\begin{array}{l}E \\
F\end{array}$ & \multirow{2}{*}{24} & \multirow{2}{*}{15,000} \\
\hline & $\mathrm{H} \rightarrow \mathrm{I}$ & $\mathrm{I} \rightarrow \mathrm{H}$ & & \\
\hline \multirow{2}{*}{9} & $\mathrm{E} \rightarrow \mathrm{F}$ & $\mathrm{F} \rightarrow \mathrm{E}$ & \multirow{2}{*}{24} & \multirow{2}{*}{13,000} \\
\hline & $\mathrm{H} \rightarrow \mathrm{I}$ & $\mathrm{I} \rightarrow \mathrm{H}$ & & \\
\hline \multirow{3}{*}{10} & $C \rightarrow D$ & $\begin{array}{l}\text { C } \\
\text { D }\end{array}$ & \multirow{3}{*}{23} & \multirow{3}{*}{30,000} \\
\hline & $\mathrm{E} \rightarrow \mathrm{F}$ & $\begin{array}{l}\mathrm{E} \\
F\end{array}$ & & \\
\hline & $\mathrm{H} \rightarrow \mathrm{I}$ & $\mathrm{I} \rightarrow \mathrm{H}$ & & \\
\hline \multirow{3}{*}{11} & $C \rightarrow D$ & $\begin{array}{l}\text { C } \\
\text { D }\end{array}$ & \multirow{3}{*}{23} & \multirow{3}{*}{28,000} \\
\hline & $\mathrm{E} \rightarrow \mathrm{F}$ & $\mathrm{F} \rightarrow \mathrm{E}$ & & \\
\hline & $\mathrm{H} \rightarrow \mathrm{I}$ & $\mathrm{I} \rightarrow \mathrm{H}$ & & \\
\hline
\end{tabular}




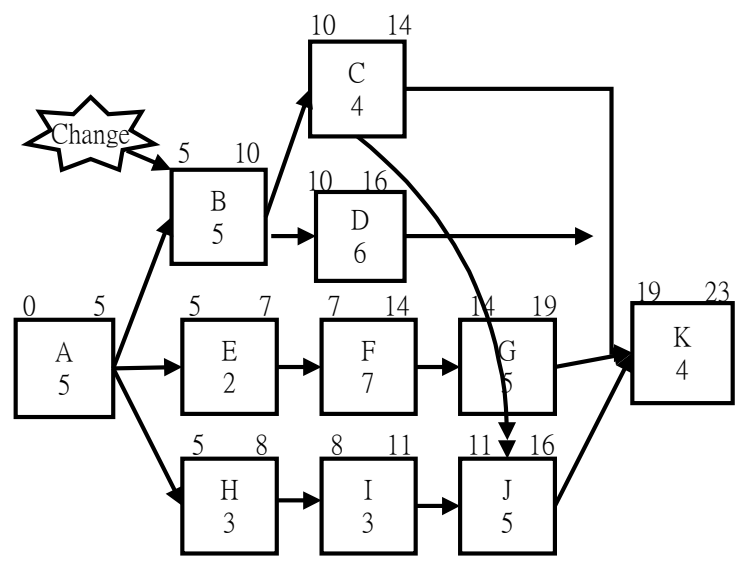

Figure 7. New Network after Revising Soft Link

Table 7. Summary of Change Impacts

\begin{tabular}{|c|c|c|c|c|}
\hline & $\begin{array}{c}\text { Direct } \\
\text { Impact }\end{array}$ & $\begin{array}{c}\text { CI (Revising } \\
\text { Links) }\end{array}$ & $\begin{array}{c}\text { CI (losing } \\
\text { productivity) }\end{array}$ & $\begin{array}{c}\text { Total } \\
\text { Impact }\end{array}$ \\
\hline Duration & 1 day & -1 day & 0 & 0 \\
\hline Cost & $\$ 80,000$ & $\$ 15,000$ & $\$ 24,000$ & $\$ 119,000$ \\
\hline
\end{tabular}

CI: Consequential Impact

\section{APPLYING TO THE PRACTICE}

In addition to the required data for establishing a schedule network, applying the LOGIC model to the industry needs other four types of data: (1) soft logical relationships, (2) impact cost of activating each soft logic, (3) causal relationships, and (4) impact cost of activating each causal logic. It is suggested that these data accompanying with the project network schedule be submitted by the contractor and reviewed by the owner. Similar to the commonly-used reviewing process of contractor's bid (for avoiding an unbalanced bid), the determination of those logic-related data is conducted in a Question/Answer and negotiable meeting. Under the constraint of a fixed project duration, the contractor provides the evidence or reason to support the existence of those logical relationships and impact costs. After a mutual agreement is reached, the determined data and the meeting records are signed by both parties and are then part of the contractual documents.

As the project proceeds, the schedule network may be updated, so do the logic-related data (which still need to be mutually agreed). Thus, when a change occurs during the course of the construction phase, the direct impact and consequential of change can be easily computed and agreed by both parites without any debatements.

\section{CONCLUSIONS AND FUTURE WORK}

The LOGIC model has contributed to three main prospects. From the research point of view, the approach of integrating different types of logic is innovative possibly for extending to solve other construction problems. Next, from the problemsolving point of view, the LOGIC model meets the key concerns in evaluating the impact of consequential impact. Then, because the algorithms of LOGIC model stays on the project level, it is believe that the model be more practical.

The on-going research tasks include: The first task is to validate the model algorithms by having feedback from the field practitioners. The second task is to develop a computer prototype. The idea is to use the Microsoft-Project scheduling software for inputting network data, the Excel spreadsheet for computing quantity and cost data, and the Visual Basic language for activating the soft and causal links. Finally, the LOGIC model should be further validated by practical problems.

\section{REFERENCES}

[1] Barrie, D. S. and Paulson, B. C., Professional Construction Management, $3^{\text {rd }}$ Edition, McGraw-Hill Inc., 1992.

[2] Construction Industry Institute, "The Impact of Changes on Construction Cost and Schedule," CII, The University of Texas, Austin, Publication 6-10, April 1990.

[3] El-Sersy, A. H., An Intelligent Data Model for Schedule Updating, Ph.D. Dissertation, University of California, Berkeley, CA, 1992.

[4] Kuprenas, J. A., Use of Influence Diagrams to Assess the Cost and Schedule Impact of Construction Changes, Ph.D. Dissertation, University of California, Berkeley, CA, 1988.

[5] Vanichvatana, S., Predicting Consequential Effects of Construction Project Changes, Ph.D. Dissertation, University of California, Berkeley, CA, 1993. 